\title{
Pilot study of a low-cost CLO test
}

We conducted a study to evaluate the validity and accuracy of McNulty's recipe for rapid diagnosis of Helicobacter pylori on antral biopsy specimens in hospital practice in Sri Lanka. Endoscopy. findings and case notes of 26 consecutive patients (male=15), who were admitted to the medical unit, Base Hospital, Panadura, and who had antral gastritis on endoscopy during a 6-month period (November 1998 to April 1999) were reviewed. All had gastric biopsies, 2 from the antrum and 2 from the corpus for histology, and 2 from the antrum for the CLO test ${ }^{\star}$ equivalent (McNulty's solution), prepared at National Hospital, Colombo.

The majority of the patients were in the 31 to 60 year age group. Endoscopy findings showed moderate to severe antral gastrits in 22, and associated duodenitis in 9. Histology showed chronic antral gastritis in 22 with Helicobactor pylori positive in 9, and negative in 1. The CLO test ${ }^{\bullet}$ equivalent was strongly positive in $24 \mathrm{~h}$ in 10 showing chronic antral gastritis, but did not become positive within the first $4 \mathrm{~h}$, as described in the literature. Six patients showed a mild positivity in $4 \mathrm{~h}$. The test showed a sensitivity of $100 \%$ and a specificity of $100 \%$.

The commercially available CLO test ${ }^{\oplus} \mathrm{kit}$ is expensive and available only in the private sector. Hence in hospital practice, the presence of $H$ pylori is confirmed at present only by histology of antral biopsies, the result of which takes at least 2 to 3 weeks even in teaching centres.
The CLO test $t^{\circ}$ which is most widely used as a bed side diagnostic test for $H$ pylori, was developed by Barry Marshall (1).

McNulty and her colleagues published an inexpensive method for routine practice (2). In practice, a positive result occurs in about $75 \%$ of cases within $2 \mathrm{~h}$, even at room temperature. Sensitivity is $90 \%$ and specificity is close to $100 \%$. The preliminary results of the study indicated that the test takes a longer time to become positive in the local setting, ie. becoming mildly positive between 4 to $6 \mathrm{~h}$, and strongly positive in $24 \mathrm{~h}$. Thus it is possible that the $H$ pylori species found locally may differ in its capacity to produce urease. The results re-confirm the usefulness of the CLO test $@$ equivalent - McNulty's recipe, as a rapid, easy to perform, sensitive and low cost bedside diagnostic test to detect the presence of $H$ pylori in biopsy samples that could be widely used in local practice.

\section{References}

1. Marshall BJ, Warren JR, Francis GJ, Blincow ED. Rapid urease test in the management of Campylobacter pylori associated gastritis. American Journal of Gastroenterology 1987; 82: 200-10.

2. McNulty CA, Dent JC, Uff JS, Gear MW, Wilkinson SP. Detection of Campylobacter pylori by the biopsy urease test; an assessment in 1445 patients. Gut 1989; 30: 1058-62.

R L Satarasinghe, Physician and, H M S Vidyathilake, Pathologist, Base Hospital, Panadura; and D H Jayamaha, Senior Registrar in Medicine, and S Siriwardane, Chemical Pathologist, National Hospital of Sri Lanka, Colombo. 